\title{
Public Opinion on Healthcare in the Context of Economic Crisis: Evidence from Portugal
}

\author{
TAMARA POPIC*, SIMONE M. SCHNEIDER** AND MARIA ASENSIO*** \\ *Department of Political and Social Sciences, European University Institute, Via dei \\ Roccettini 9, 1-50014 San Domenico di Fiesole, Italy \\ email: tamara.popic@eui.eu \\ ** Max Planck Institute for Social Law and Social Policy, Amalienstrasse 33, 80799 Munich, \\ Germany \\ email: s.schneider@mpisoc.mpg.de \\ ****ISCTE - University Institute of Lisbon, Av. das Forças Armadas, 1649-026 Lisboa, \\ Portugal \\ email: maria.asensio@iscte-iul.pt
}

\begin{abstract}
This article investigates to what extent austerity-oriented measures introduced in the Portuguese health sector during the recent economic crisis were associated with changes in the public opinion on healthcare. We conducted multivariate regression analyses of crosssectional, biannual data from the European Social Survey (2002-2015) for 13,271 individuals living in private households in Portugal. In line with our expectations, healthcare evaluations of the general population improved until 2010 but declined with the implementation of comprehensive austerity measures introduced under the Memorandum of Understanding after 2011. Healthcare evaluations of vulnerable social groups - older and retired individuals, individuals with poor health, low income and education - declined particularly strongly. In addition, differences in healthcare evaluations between more and less vulnerable social groups were more pronounced after 2011. Interestingly, healthcare evaluations of the general population and of some of the most vulnerable groups 'recovered' in 2015, when most of the Memorandum measures were implemented. Our findings contribute to the literature on the effects of austerity measures on welfare attitudes and stress the need to analyse the differential impact of crisis-induced welfare state reforms across social groups.
\end{abstract}

\section{Introduction}

Welfare states face increasing pressure to reform in the context of population ageing and new social risks. The recent economic crisis intensified these pressures, especially for those European governments faced with rising unemployment and growing public debt. In some cases, policy-makers embraced comprehensive reforms marked by external conditionality and austerity aimed at reducing public sector expenditures, including those dedicated to the welfare sector. While the character of these crisis-triggered welfare reforms has been subject to close analysis (see e.g. Farnsworth and Irving, 2011; Greve, 2014; Shahidi, 2015; Ronchi, 
2018; Schneider and Devitt, 2018a), little is known about their impact on public opinion.

This article aims to fill this gap. It analyses the effects of healthcare reforms in the context of the recent economic crisis and subsequent austerity, on the public's evaluation of the Portuguese healthcare system. Portugal was hard hit by the crisis, with growing government debt, rising unemployment and financial instability. As a response, the government introduced a set of austerity measures but, as these failed to stop the crisis, in 2011, it signed a bailout agreement, the Memorandum of Understanding (MoU), with the 'Troika' - the European Central Bank, European Commission and International Monetary Fund. Under the MoU, the Troika gave Portugal financial assistance in exchange for the implementation of a much more comprehensive set of austerity measures, extensively targeting the healthcare sector. In this study, we investigate whether Portuguese public opinion on healthcare has been responsive to these austerity measures and whether opinions differ across social groups.

Understanding public opinion on healthcare in the context of economic crisis is relevant for several reasons. For one thing, it can serve as a litmus-test of welfare state performance. One of the key roles of the welfare state is to protect its citizens, especially the most vulnerable, from risks and uncertainties (Barr, 2001). The provision of and access to good quality medical care is crucial during economic crises to alleviate experiences of economic hardship, as these can have detrimental effects on health (Stuckler et al., 2011, 2017; Schrecker and Bambra, 2015). Negative opinions on healthcare in the context of crisis could therefore suggest failures in a welfare state's performance at a time when its support is most needed. In addition, changes in healthcare evaluations can signal changes in the public mood. A decline in the image of healthcare, one of the largest welfare sectors, can suggest a general decline in perceptions of the welfare state, with possibly significant consequences for its legitimacy (see Vis et al., 2011; Roosma et al., 2013). How an economic crisis shapes opinions towards healthcare can be crucial for the future of the healthcare system and welfare programmes more generally. While the positive views can legitimate the status quo and function as a defence mechanism against radical reforms, negative views of the welfare state and its performance could indicate low acceptability of the existing welfare arrangements, paired with unfulfilled expectations of the welfare system, creating pressure for policy change (see Kohl and Wendt, 2004).

\section{Public opinion on healthcare}

Various factors influence public opinion on the performance of the healthcare system, such as institutional characteristics of the healthcare system or the demographic and socioeconomic characteristics of the individual (Mossialos, 1997; Kohl and Wendt, 2004; Wendt et al., 2010; Missinne et al., 2013; Borisova et al., 
2017; Popic and Schneider, 2018). On the one hand, high levels of (public) healthcare spending or generous supplies of healthcare services in the form of a high density of general practitioners (GPs) increase satisfaction with the health system. On the other hand, high levels of private spending in the form of out-ofpocket payments for medical goods and services contribute to public dissatisfaction. Research also shows that satisfaction with the healthcare system differs across population groups and is related to the respondent's demographic and socioeconomic background as this is connected to his or her specific needs, interests, values and expectations (Wendt et al., 2010; Missinne et al., 2013; Footman et al., 2013; Borisova et al., 2017). Generally speaking, women, the elderly, and individuals with low income and poor health are less satisfied with the healthcare system than men, the young and those with higher economic status and better health.

While studies show that healthcare evaluations are influenced by both the institutional characteristics of the healthcare system and the personal characteristics of the respondent, there are reasons to believe the influence of these two factors will be particularly salient in the context of economic crisis. Periods of deteriorating and unstable economic conditions generate unemployment, debt and financial strain, all of which have a strong adverse effect on health, with the most vulnerable being particularly affected (Kentikelenis et al., 2011; Sakellarides et al., 2014; Stuckler et al., 2011, 2017). Crisis also often triggers policy reforms. During the recent economic crisis, health policy in many European countries, especially those hardest hit by the crisis, was dominated by austerity. Austerity generally implied cuts in public healthcare spending and the introduction of measures inspired by the 'new public management' approach, which aimed at cost-saving and increased efficiency in the financing and provision of healthcare delivered by the public sector. In some cases, these cuts were severe and caused significant changes in the healthcare systems' institutional organisation, with a concomitant impact on users' experience by, for example, increasing waiting times or shifting the costs of care onto patients (Mladovsky et al., 2012; Karanikolos et al., 2013; Pavolini and Guillén, 2013; Thomson et al., 2014).

So far, the research on the economic crisis and its consequences for public opinion has focused on changes in normative attitudes, such as attitudes towards redistribution or the state's role in welfare provision (e.g. Blekesaune, 2007, 2013; Margalit, 2013). Studies have found that, for example, crisis phenomena such as lower employment rates and personal experience of economic hardship are associated with stronger support for redistribution and government responsibility for welfare provision. Even people who do not experience economic hardship show stronger support for redistribution if they are living in countries where many other people report economic hardship (Blekesaune, 2013), a finding that emphasises the contextual dimension of welfare attitudes. While these 
findings are interesting, they do not explore public views towards the performance of the welfare state or its specific sectors during crisis. Although we know normative attitudes, such as expectations towards the government role in providing healthcare, are inversely related to the general evaluation of healthcare services (Schneider and Popic, 2018), we can only speculate on whether crisis and austerity also affected the views of the performance of the healthcare system in Portugal.

\section{The Portuguese healthcare system in the context of crisis}

\subsection{The Portuguese healthcare system}

The Portuguese healthcare system is a mix of a universal, tax-financed public system and a system financed by social and private insurance schemes. The universal, tax-financed system is based on the National Health Service (NHS) model of healthcare; it provides medical care to the whole population on the basis of residence but, like other NHS systems, it is characterised by long waiting times (Bentes et al., 2004). Specific social groups can access and receive faster and better quality healthcare services through either social insurance or voluntary private health insurance schemes. Social insurance schemes, also known as healthcare 'subsystems' (subsistemas), cover specific occupational groups and allow their beneficiaries free choice of healthcare providers and use of private healthcare facilities (Pereirinha, 1995; see also Guillén, 2002; Bentes et al., 2004). ${ }^{1}$ Voluntary private insurance schemes are mostly available to high earners and employees of private companies; they too offer supplementary coverage that allows free provider choice and access to private facilities, permitting their beneficiaries to skip the long waiting times in the public healthcare sector (Bentes et al., 2004; Thomson and Mossialos, 2007). ${ }^{2}$ From a systemic point of view, the specific mix of public, social and private insurance has created a dual system in which the better-off enjoy privileged access and conditions of care, while the more vulnerable, such as the unemployed, the old, the poor, and the disabled, rely on public healthcare (see Pereirinha, 1995).

\subsection{Changes in the Portuguese healthcare system in the context of the financial crisis}

In early 2010, Portugal was hit by the global financial crisis. An initial series of reforms in response to the crisis were introduced in three austerity packages in 2010 that sought to bring down the fiscal deficit (Afonso et al., 2015). Some of these reforms targeted the healthcare system. One replaced obligatory with voluntary enrolment in the largest social health insurance fund (ADSE). Another featured cuts aimed at public sector employees, and thus NHS workers, including freezes and reductions of salaries. However, not all measures implied cuts, as one increased tax deductions for private health insurance. 
Nevertheless, the country's economic conditions progressively worsened and the Portuguese government sought rescue in May 2011 by signing the above-mentioned MoU with the Troika. Under the MoU, Portugal would be given external financial assistance worth $€ 78$ billion in exchange for a series of radical austerity reforms. In the healthcare sector, these implied drastic cuts expected to result in $€ 668$ million savings, achieved through the implementation of a comprehensive set of more than 30 measures (European Commission, 2011; see also Barros, 2012a, 2012b; Sakellarides et al., 2014). Table 1 gives an overview of some of the main $\mathrm{MoU}$ measures. Compared to the initial crisis measures of the Portuguese government (2010-2011), those implemented after the MoU (2012-2015) were more comprehensive and targeted more intensively both the general population and specific social groups, suggesting a stronger impact on provision of and access to healthcare services.

One of the first measures aimed at reducing public spending for pharmaceuticals by introducing reference pricing and promoting generic medicines; this, in turn, led to a reduction in the price of medicine (Barros, 2012c). Another measure involved increases in out-of-pocket payments through significant increases (in some cases, more than 100 per cent) in user fees (taxas moderadoras) for a wide range of health services, but specific social groups (e.g. children, the chronically ill) were exempted from these fees. Other austerity measures targeted the healthcare privileges of those with private and social insurance by eliminating tax deductions for private healthcare spending for the highest income categories, reducing tax deductions for spending on private healthcare insurance and increasing employee contributions to ADSE, the social health insurance for civil servants. The MoU measures also called for the continuation of previously introduced salary freezes and reductions for NHS staff but, at the same time, sought improvements in primary care by increasing the supply of family doctors.

The implementation of the MoU measures was coupled with severe cuts in healthcare spending. The total healthcare expenditure (THE, per capita) increased strongly, from $€_{1584}$ in 2008 to $€_{1671}$ in 2010 , but decreased to $€_{1480}$ in 2013 . Then it rose again to $€_{1557}$ in 2015 . At the same time, public spending for healthcare (as \% of THE) increased from 68.4 per cent in 2008 to 69.8 per cent in 2010; it decreased to 65.6 per cent in 2012 and had not fully recovered by 2015 (66.2 per cent). At the same time, out-of-pocket (OOP) spending (as \% of THE) was lowest in 2010 at 24.6 per cent but increased to 28.2 per cent in 2012. In 2015, it was still high, at 27.7 per cent of THE. The impact of the MoU measures was less evident in the supply of health services. While there were no changes in the density of hospital beds (beds per 1000 population), the density of GPs and specialists increased continuously between 2008 and 2015, rising from 1.8 to 2.4 and from 1.9 to 2.3 (per 1000 population) for GPs and specialists respectively (OECD, 2017). This suggests that, as intended, 
TABLE 1. Austerity measures introduced in the Portuguese healthcare systems during the crisis

\begin{tabular}{|c|c|c|c|c|}
\hline Policy theme & Policy provision & Law & $\begin{array}{l}\text { Introduction } \\
\text { date }\end{array}$ & $\begin{array}{l}\text { Implementation } \\
\text { date }\end{array}$ \\
\hline Healthcare subsystems & Enrolment in ADSE (subsystems for civil servants) becomes optional. & Law no. $3-\mathrm{B} / 2010$ & $28 / 04 / 2010$ & $29 / 04 / 2010$ \\
\hline Private insurance & Introduction of $30 \%$ tax deduction for private healthcare insurance. & Law no. $55-\mathrm{A} / 2010$ & $31 / 12 / 2010$ & $01 / 01 / 2011$ \\
\hline NHS staff & $\begin{array}{l}\text { Salary freezes and reductions, stop on promotions, reductions of } \\
\text { existing staff and new hirings, of overtime hours, of amounts paid for } \\
\text { overtime work and of retirement benefits for public sector workers. } \\
\text { Signing of the Memorandum of Understanding on } 17 \text { May } 2011\end{array}$ & Law no. $55-\mathrm{A} / 2010$ & $31 / 12 / 2010$ & $01 / 01 / 2011$ \\
\hline Pharmaceuticals & $\begin{array}{l}\text { Introduction of external reference pricing. } \\
\text { Price reduction of generic medicines: setting of the maximum price } \\
\text { of the generic drug at least } 50 \% \text { lower than the price of the branded } \\
\text { product with similar substance. }\end{array}$ & $\begin{array}{l}\text { Decree-law } \\
\text { no. } 112 / 2011\end{array}$ & $29 / 11 / 2011$ & $01 / 01 / 2012$ \\
\hline User fees & 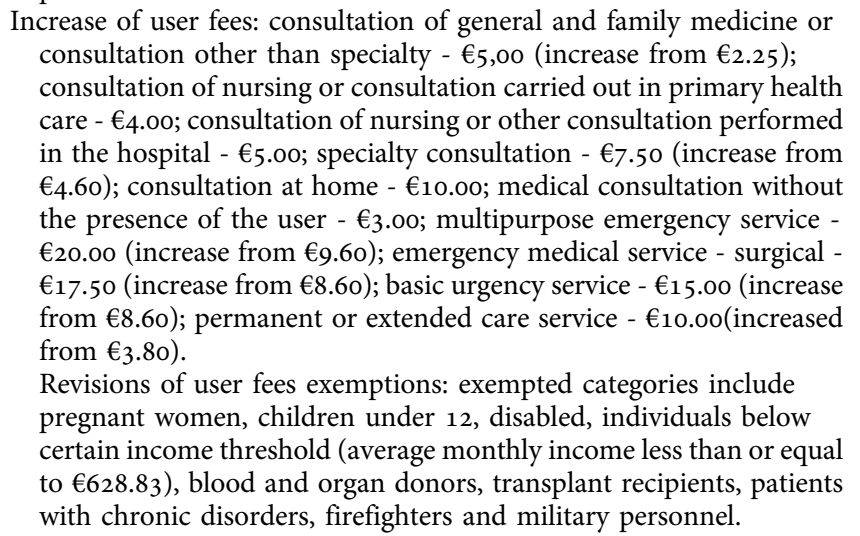 & $\begin{array}{l}\text { Decree-Law } \\
\text { no. } 113 / 2011\end{array}$ & $29 / 11 / 2011$ & $01 / 01 / 2012$ \\
\hline
\end{tabular}


TABLE 1. Continued

\begin{tabular}{|c|c|c|c|c|}
\hline Policy theme & Policy provision & Law & $\begin{array}{l}\text { Introduction } \\
\text { date }\end{array}$ & $\begin{array}{l}\text { Implementation } \\
\text { date }\end{array}$ \\
\hline $\begin{array}{l}\text { Private healthcare } \\
\text { spending }\end{array}$ & $\begin{array}{l}\text { Elimination of tax deductions for private healthcare spending } \\
\text { for the top two income brackets. } \\
\text { Reduction of tax deductions for private health insurance } \\
\text { spending from } 30 \% \text { to } 10 \% \text {. }\end{array}$ & Law no. $64-\mathrm{A} / 2011$ & $30 / 12 / 2011$ & $04 / 01 / 2012$ \\
\hline User fees & $\begin{array}{l}\text { Revisions of user fees exemptions: unemployed added as } \\
\text { exempted category. }\end{array}$ & Law no. $128 / 2012$ & $21 / 06 / 2012$ & $22 / 06 / 2012$ \\
\hline Health subsystems & $\begin{array}{l}\text { Increase of employee contribution for the social health insurance } \\
\text { from } 1.5 \text { to } 2.25 \% \text { of the salary. } \\
\text { For pensioners, contribution for social health insurance set } \\
\text { at } 2.5 \% \text { of the pension. }\end{array}$ & $\begin{array}{l}\text { Decree-Law no. } \\
105 / 2013\end{array}$ & $30 / 07 / 2013$ & $31 / 07 / 2013$ \\
\hline Healthcare subsystems & $\begin{array}{l}\text { Further increase in employees contributions for social health } \\
\text { insurance to } 3.5 \% \text { of the salary. }\end{array}$ & Law no. 30/2014 & $19 / 05 / 2014$ & $20 / 05 / 2014$ \\
\hline NHS staff & $\begin{array}{l}\text { Continuation of salary freezes and reductions, stop on promotions } \\
\text { and other saving measures concerning the public sector workers. } \\
\text { Introduction of performance bonuses or other cash benefits of a } \\
\text { related nature. }\end{array}$ & Law no. $82-\mathrm{B} / 2014$ & $31 / 12 / 2014$ & $01 / 01 / 2015$ \\
\hline Primary care & $\begin{array}{l}\text { Increasing the number of Family Health Units (Unidades de Saúde } \\
\text { Familiar) and setting-up a mechanism to guarantee the presence of } \\
\text { family doctors in needed areas to induce a more even distribution. }\end{array}$ & $\begin{array}{l}\text { Decree-Law no. } \\
223 / 2015\end{array}$ & $08 / 10 / 2015$ & $09 / 10 / 2015$ \\
\hline
\end{tabular}


the austerity measures mainly affected healthcare spending, especially spending by public sources and out-of-pocket spending, while the supply of healthcare services remained unaffected or increased.

\subsection{Access to healthcare in the context of crisis}

Studies show that, with the implementation of the Troika's austerity measures, the Portuguese population had difficulties accessing care. Waiting times for the most common procedures, such as cataract surgery, decreased until 2011 but started to increase again in 2012 (OECD, 2017). Evidence also shows a decrease in the number of GP appointments and an increase in the number of missed NHS appointments (Sakellarides et al., 2014). An increased share of the population had unmet healthcare needs for cost reasons following the implementation of the MoU (Eurostat, 2017).

Further, despite the measures intended to protect the most vulnerable, such as user fee exemptions, studies on the experiences of different social groups within the Portuguese healthcare system suggest the austerity effect was particularly strong for some of the most vulnerable social groups. Increases in user fees for primary and hospital care and difficulties in the implementation of exemptions may explain why accessibility to healthcare and medication deteriorated for elderly and chronically ill patients and had a negative effect for those living in disadvantaged areas (Legido-Quigley et al., 2016; Costa et al., 2017; Tavares and Zantomio, 2017). Additional evidence indicates the share of the population experiencing unmet healthcare needs for cost reasons after the MoU increased more dramatically for the lowest income quintile than for the highest income quintile (Eurostat, 2017). A similar trend is observed for unmet needs across age and gender groups; even though unmet needs increased for both subgroups, the increase was stronger for the older than for the younger, and for women than for men (Eurostat, 2017; see also Thomson et al., 2014; Doetsch et al., 2017).

\section{Hypotheses}

These findings allow us to speculate that the austerity measures introduced into the Portuguese healthcare system during the crisis had an effect on the healthcare evaluations of the general population and, more specifically, on the evaluations of particular social groups. The scope and degree of the austerity measures implemented under the MoU (after 2011) were much higher than the scope and degree of the initial crisis measures (until 2011) and more strongly affected users of public healthcare services. Lower total and public healthcare spending, increases in out-of-pocket payments for health services, and adverse experiences in gaining access to health services suggest public opinion towards the healthcare system was likely to be more negative after the implementation of the MoU measures. Thus, the effect of crisis on public evaluations of healthcare 
services may only become visible after the implementation of the MoU measures. Specifically, we expect healthcare evaluations of the Portuguese population to have dropped in 2012 after the implementation of the MoU measures (H1). However, whether the MoU measures had a long-lasting effect on public opinion towards healthcare remains an open empirical question. After 2012, total healthcare spending increased until 2015 and this may have had an ameliorative effect on opinion. That said, however, out-of-pocket payments (as \% THE) remained high, and public health expenditure (as \% THE) only slightly increased again suggesting a long-term effect of the crisis measures on public opinion, with healthcare evaluations kept correspondingly low.

Further, we expect the drop in healthcare evaluations in 2012 to be stronger for more vulnerable social groups, such as the old and non-employed, individuals with low income and education, and poor health status. As previously shown, these subgroups depend more strongly on the public NHS system and were more affected by the crisis. Thus, MoU measures, such as the introduction of user fees for NHS services, as well as cuts in public healthcare expenditure, had more severe consequences for them. We therefore expect to find healthcare evaluations of individuals belonging to more vulnerable social groups, such as older and non-employed individuals, as well as those with low income, education, and health status, to have dropped more strongly in 2012 than the evaluations of those belonging to the more advantaged social groups $\left(\mathrm{H}_{2}\right)$. At the same time, and as a direct consequence of Hypothesis 2, we expect differences between healthcare evaluations of the more and the less vulnerable social groups would be more pronounced after the implementation of the MoU measures $\left(\mathrm{H}_{3}\right)$.

\section{Data and Methods}

\subsection{Data}

The empirical analysis was based on the Portuguese sample of the European Social Survey (ESS), a high quality, cross-comparative data set providing biennial information representative of the European population aged 15 and above living in private households. The ESS follows a repeated cross-sectional design, and respondents are selected using strict probability sampling. Data were collected via face-to-face interviews. This study used all seven waves of the Portuguese sample of the ESS survey, covering a time span of 13 years (2002-2015). With the exception of round 7, fieldwork started in September/ October of the indicated survey year and ended in the first months of the next calendar year. Response rates varied between rounds and ranged from 67 per cent in $2010 / 11$ to 77 per cent in $2012 / 13 .{ }^{3}$ An exception is round 7 , which was sampled in 2015, and had a response rate of only 43 per cent. In total, the Portuguese sample includes 13,271 individuals for whom information on all variables across years is available. 


\subsection{Variables}

Evaluation of healthcare services was the main dependent variable in our analysis. In the survey, respondents were asked what they 'think overall about the state of health services in their country nowadays' on an 11-point scale ranging from o (extremely bad) to 10 (extremely good).

We measured changes in the evaluation of healthcare services using time dummy variables for each survey year. To explore subgroup differences in healthcare evaluations, we included respondents' demographic and socio-economic characteristics, such as sex/gender $(1=$ female, $0=$ male), age $(<21,21-35$, $36-49,50-64,65+$ years), and migration background ( $1=$ born outside country of residence, $\mathrm{o}=$ born in country of residence). To test for health needs, we included two health variables: self-reported health status measured on a 5-point scale, ranging from very good to good, fair, bad, and very bad health; and health related limitations in daily lives and routines re-coded into a dummy variable ( $1=\mathrm{a}$ lot/to some extent, $\mathrm{o}=$ no limitations). Since information on household income is missing for wave 5 in the Portuguese dataset, we used a subjective income variable as a proxy for the financial resources available to the household. Survey respondents were asked how they 'feel about their household income nowadays' and whether they live comfortably on present income, cope on present income, find it difficult to live on present income, or find it very difficult to live on present income. We also included current status of employment (paid work, in education, unemployed, retired, disabled/long-term sick, and other employment status) and distinguished between three educational groups: respondents with completed lower secondary education or less (ISCED1/2, 'lower educated'), those with upper secondary education and post-secondary non-tertiary education (ISCED 3/4, 'middle educated'), and those with tertiary education (ISCED 5, 'higher educated'). To control for other household-specific characteristics, we included presence of a partner living in the household $(1=\mathrm{yes}, \mathrm{o}=\mathrm{no})$, the household size, and whether children are currently living in the household $(1=$ yes, $\mathrm{o}=$ no).

We tested the sensitivity of our findings on healthcare services by comparing them to results on the evaluation of the state of education (see Schneider and Devitt, 2018b). This indicator has also been included in all seven rounds of the ESS and has been measured on a similar response scale. Respondents were asked what they think overall about the state of education in their country nowdays, on an 11-point scale ranging from o (extremely bad) to 10 (extremely good). An overview of the dependent and independent variables is provided in the supplementary online material (Table A1).

\subsection{Methods}

We applied ordinary least square (OLS) regression analysis with robust standard errors using the Huber-White-sandwich estimator. Changes in subgroup 
differences across time were based on time-specific regression analysis for the following time periods: pre-crisis (2002-2007), the first crisis period (20082011), and the second crisis period which coincided with the implementation of the MoU measures (2012-2015) (see Table 2). ${ }^{4}$ To analyse the changes in healthcare evaluations for different population groups over time, we calculated interaction effects between subgroups and year of survey based on the pooled sample (2002-2015) (see Table 3). At all stages, we included demographic and socio-economic characteristics of the individual. To ensure representative estimations for the Portuguese population, we applied standard weights following the recommendations of the ESS. Note that we could not empirically test intraindividual changes in evaluations across time, as data are cross-sectional. Therefore, any assumptions as to causality remain speculative and require the inclusion of relevant indicators in longitudinal survey studies.

\section{Results}

\subsection{Trends in healthcare evaluations for general population over time}

Portuguese residents rated their healthcare services particularly low in 2002, with a mean of $3.30(\mathrm{SD}=2.13)$. After that point, evaluations increased steadily, at least until 2010/11. Figure 1 gives an overview of changes in healthcare evaluations between 2010 and 2015, along with the major healthcare reforms introduced during this period. In 2010/11, evaluations reached a mean of 4.52 $(\mathrm{SD}=2.17)$. With the signing of the $\mathrm{MoU}$ and the implementation of certain key austerity measures, evaluations dropped to a mean of $3.99(\mathrm{SD}=2.28)$ in 2012/13. Despite the ongoing reform processes and the implementation of MoU measures until 2015, healthcare evaluations increased again in 2015 to $4.62(\mathrm{SD}=2.56)$, slightly above the mean in 2010/11.

The results of the linear regression analysis support the above stated trends, even after controlling for standard demographic and socio-economic characteristics (Table 2, Model 1). Overall, healthcare evaluations increased gradually but significantly between 2002 and 2010. In 2010/11, evaluations were 1.27 scale points $(\mathrm{SE}=.10)$ higher than in $2002 / 03$ and 0.28 scale points $(\mathrm{SE}=.08)$ higher than in 2008/o9 (Table 3, Model 2). In line with Hypothesis 1, with the implementation of the MoU measures, evaluations dropped by 0.43 scale points $(\mathrm{SE}=.09)$ in $2012 / 13$ from levels in $2010 / 11$; they were even lower than in 2008/09 $(\beta=-.15, \mathrm{SE}=.08)$. Surprisingly, however, despite continued health policy interventions and crisis management after 2012, evaluations 'recovered' in 2015 and reached a level comparable to $2010 / 11$.

\subsection{Trends in healthcare evaluations for different subgroups over time}

With the implementation of the MoU measures, healthcare evaluations dropped comparatively strongly for vulnerable and socially disadvantaged 


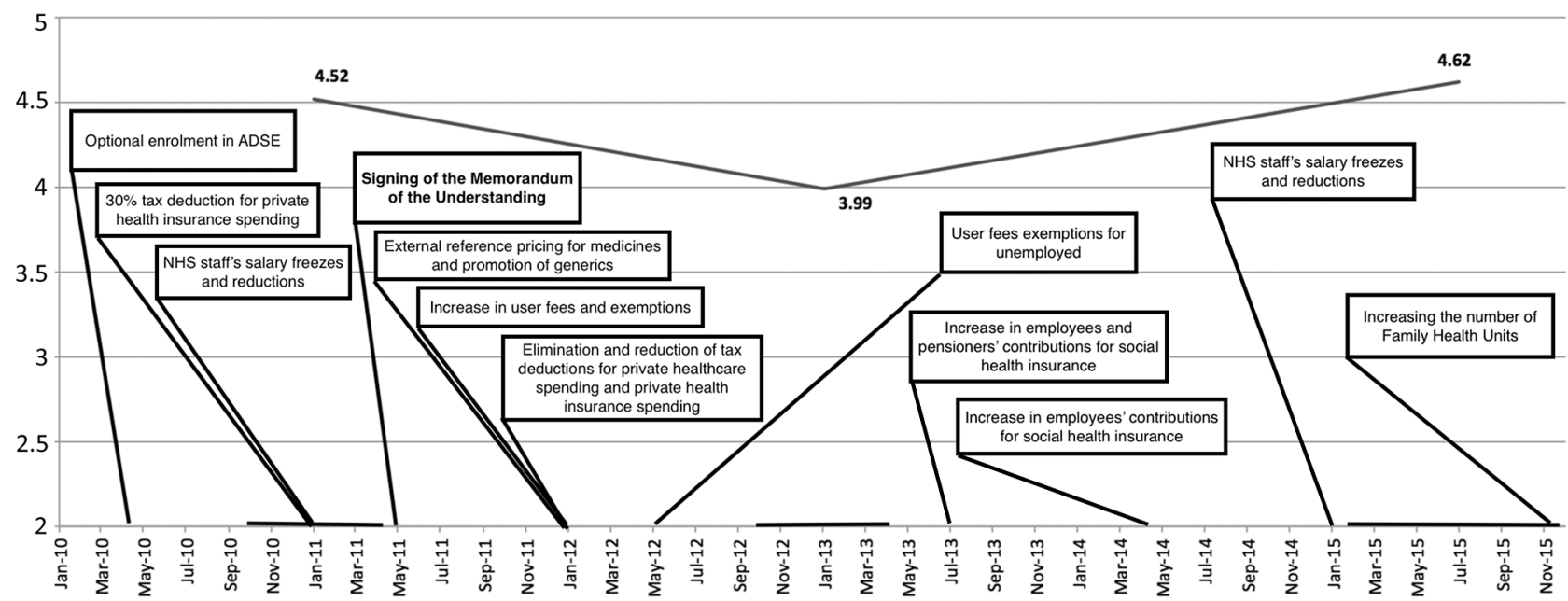

Figure 1 Evaluations of healthcare services and austerity measures in Portugal in the context of crisis

Note: The figure shows mean values of healthcare evaluations in Portugal for ESS waves 5 (2010/11), 6 (2012/13) and 7 (2015). Bold lines on the x-axis mark the periods of the European Social Survey fieldwork in Portugal. 
TABLE 2. Determinants of healthcare evaluations - Results of linear regression models (2002-2015)

\begin{tabular}{|c|c|c|c|c|c|c|c|c|}
\hline & \multicolumn{2}{|c|}{ (1) $2002-2015$} & \multicolumn{2}{|c|}{ (2) 2002-2006 } & \multicolumn{2}{|c|}{ (3) $2008-2010$} & \multicolumn{2}{|c|}{ (4) $2012-2015$} \\
\hline & $\beta$ & SE & $\beta$ & SE & $\beta$ & SE & $\beta$ & SE \\
\hline \multicolumn{9}{|l|}{ Year of Survey } \\
\hline 2002 & $-0.99^{* * *}$ & $(0.09)$ & $-0.39^{* * *}$ & $(0.09)$ & & & & \\
\hline 2004 & $-0.76^{* * *}$ & $(0.08)$ & $-0.14^{+}$ & $(0.08)$ & & & & \\
\hline 2006 & $-0.63^{* * *}$ & $(0.08)$ & Ref. & & & & & \\
\hline 2008 & Ref. & & & & Ref. & & & \\
\hline 2010 & $0.28^{* * *}$ & $(0.08)$ & & & $0.27^{* * *}$ & $(0.08)$ & & \\
\hline 2012 & $-0.15^{+}$ & $(0.08)$ & & & & & Ref. & \\
\hline 2015 & $0.22^{*}$ & $(0.10)$ & & & & & $0.39^{* * *}$ & $(0.11)$ \\
\hline \multicolumn{9}{|l|}{ Socio-Demographic Characteristics } \\
\hline Female $(0=$ male $)$ & -0.06 & $(0.05)$ & -0.09 & $(0.08)$ & -0.08 & $(0.08)$ & -0.02 & $(0.11)$ \\
\hline \multicolumn{9}{|l|}{ Age Groups $(0=36-49)$} \\
\hline$<21$ & $0.35^{*}$ & $(0.16)$ & $0.59^{*}$ & $(0.24)$ & 0.16 & $(0.25)$ & -0.10 & $(0.29)$ \\
\hline $21-35$ & $0.15^{*}$ & $(0.08)$ & $0.22^{+}$ & $(0.11)$ & 0.14 & $(0.13)$ & 0.04 & $(0.16)$ \\
\hline $50-64$ & 0.10 & $(0.08)$ & -0.13 & $(0.12)$ & 0.19 & $(0.14)$ & $0.32^{*}$ & $(0.16)$ \\
\hline $65+$ & $0.44^{* * * *}$ & $(0.11)$ & $0.27^{+}$ & $(0.16)$ & $0.47^{* *}$ & $(0.18)$ & $0.60^{* *}$ & $(0.23)$ \\
\hline Foreign Born (o = inborn) & $0.72^{* * *}$ & $(0.10)$ & $0.54^{* * *}$ & $(0.16)$ & $0.96^{* * *}$ & $(0.18)$ & $0.68^{* * *}$ & $(0.20)$ \\
\hline \multicolumn{9}{|l|}{ Subj. Health $(\mathrm{o}=\mathrm{v}$. good $)$} \\
\hline good & -0.07 & $(0.09)$ & 0.17 & $(0.14)$ & -0.11 & $(0.15)$ & $-0.27^{+}$ & $(0.16)$ \\
\hline fair & -0.14 & $(0.10)$ & 0.11 & $(0.15)$ & -0.09 & $(0.17)$ & $-0.48^{* *}$ & $(0.18)$ \\
\hline bad & $-0.56^{* * *}$ & $(0.13)$ & -0.21 & $(0.20)$ & -0.31 & $(0.22)$ & $-1.26^{* * *}$ & $(0.25)$ \\
\hline v. bad & $-1.21^{* * *}$ & $(0.21)$ & $-0.94^{* *}$ & $(0.32)$ & $-0.84^{*}$ & $(0.38)$ & $-1.93^{* * *}$ & $(0.42)$ \\
\hline Health Limitations $(\mathrm{o}=$ no limitations $)$ & $0.19^{*}$ & $(0.08)$ & 0.03 & $(0.13)$ & 0.11 & $(0.13)$ & $0.53^{* * *}$ & $(0.16)$ \\
\hline \multicolumn{9}{|l|}{ Socio-Economic Characteristics } \\
\hline \multicolumn{9}{|l|}{ Employment Status (o $=$ in paid work) } \\
\hline In education & $0.41^{* *}$ & $(0.12)$ & 0.22 & $(0.19)$ & $0.66^{* *}$ & $(0.20)$ & $0.68^{* *}$ & $(0.24)$ \\
\hline Unemployed & 0.14 & $(0.09)$ & 0.20 & $(0.16)$ & 0.18 & $(0.17)$ & 0.09 & $(0.16)$ \\
\hline Retired & 0.06 & $(0.09)$ & 0.12 & $(0.14)$ & 0.14 & $(0.16)$ & -0.12 & $(0.19)$ \\
\hline Disabled/long-term sick & 0.30 & $(0.25)$ & 0.50 & $(0.35)$ & 0.60 & $(0.42)$ & -0.34 & $(0.52)$ \\
\hline Others & $0.20^{*}$ & (o.09) & $0.28^{*}$ & $(0.13)$ & 0.22 & $(0.17)$ & 0.06 & $(0.21)$ \\
\hline
\end{tabular}


TABLE 2. Continued

\begin{tabular}{|c|c|c|c|c|c|c|c|c|}
\hline & \multicolumn{2}{|c|}{ (1) 2002-2015 } & \multicolumn{2}{|c|}{ (2) 2002-2006 } & \multicolumn{2}{|c|}{ (3) 2008-2010 } & \multicolumn{2}{|c|}{ (4) $2012-2015$} \\
\hline & $\beta$ & SE & $\beta$ & SE & $\beta$ & SE & $\beta$ & SE \\
\hline \multicolumn{9}{|c|}{ Subj. HH Income (o = living comfortably) } \\
\hline coping & $-0.26^{* *}$ & $(0.10)$ & $-0.38^{* *}$ & $(0.14)$ & -0.20 & $(0.15)$ & -0.15 & $(0.21)$ \\
\hline difficult & $-0.50^{* * *}$ & $(0.10)$ & $-0.39^{*}$ & $(0.16)$ & $-0.55^{* * *}$ & $(0.17)$ & $-0.60^{* *}$ & $(0.22)$ \\
\hline very difficult & $-0.69^{* * *}$ & $(0.13)$ & $-0.63^{* * *}$ & $(0.19)$ & $-0.76^{* * *}$ & $(0.21)$ & $-0.73^{* *}$ & $(0.26)$ \\
\hline \multicolumn{9}{|l|}{ Education $(\mathrm{o}=$ low education $)$} \\
\hline medium & $-0.21^{* *}$ & $(0.07)$ & $-0.26^{*}$ & $(0.10)$ & $-0.24^{+}$ & $(0.12)$ & -0.11 & $(0.15)$ \\
\hline high & 0.08 & $(0.08)$ & 0.13 & $(0.13)$ & -0.08 & $(0.13)$ & 0.13 & $(0.16)$ \\
\hline \multicolumn{9}{|l|}{ HH-Characteristics } \\
\hline Partner $(\mathrm{o}=$ no partner in $\mathrm{HH})$ & 0.00 & $(0.06)$ & -0.04 & $(0.09)$ & -0.14 & $(0.10)$ & 0.18 & $(0.11)$ \\
\hline HH Size & $0.09^{* * *}$ & $(0.03)$ & 0.03 & $(0.04)$ & $0.12^{*}$ & $(0.05)$ & $0.15^{* *}$ & $(0.06)$ \\
\hline Kids in $\mathbf{H H}$ ( $\mathrm{o}=$ no kids $)$ & $-0.11^{+}$ & $(0.06)$ & -0.02 & $(0.10)$ & -0.09 & $(0.11)$ & $-0.28^{+}$ & $(0.14)$ \\
\hline Constant & $4.27^{* * *}$ & $(0.16)$ & $3.72^{* * *}$ & $(0.25)$ & $4.22^{* * *}$ & $(0.25)$ & $4.09^{* * *}$ & $(0.31)$ \\
\hline $\mathbf{R}_{2}$ & 0.07 & & 0.04 & & 0.05 & & 0.06 & \\
\hline $\mathbf{N}$ & 13271 & & 5525 & & 4395 & & 3351 & \\
\hline
\end{tabular}

Note: ESS, Portuguese Sample, rounds $1-7$, unstandardised coefficients, standard errors in parentheses, standard weights applied. ${ }^{+} p<0.10{ }^{*} p<0.05$,

** $p<0.01,{ }^{* * *} p<0.001$. 
TABLE 3. Changes in healthcare evaluations over time 'within' subgroups Results of interaction effects

(1) $\Delta 2008-2010$

\begin{tabular}{|c|c|c|c|}
\hline Overall Population & $\begin{array}{l}0.28^{* * *} \\
(0.08)\end{array}$ & $\begin{array}{c}-0.43^{* * *} \\
(0.09)\end{array}$ & $\begin{array}{l}0.37^{* * * *} \\
(0.11)\end{array}$ \\
\hline \multicolumn{4}{|l|}{ Age Groups } \\
\hline$<21$ & $\begin{array}{c}0.22 \\
(0.28)\end{array}$ & $\begin{array}{c}-0.48 \\
(0.33)\end{array}$ & $\begin{array}{c}0.23 \\
(0.39)\end{array}$ \\
\hline $21-35$ & $\begin{array}{c}0.32+ \\
(0.18)\end{array}$ & $\begin{array}{c}-0.32 \\
(0.20)\end{array}$ & $\begin{array}{c}0.16 \\
(0.25)\end{array}$ \\
\hline $36-49$ & $\begin{array}{c}0.26 \\
(0.17)\end{array}$ & $\begin{array}{r}-0.36^{*} \\
(0.17)\end{array}$ & $\begin{array}{l}0.36+ \\
(0.21)\end{array}$ \\
\hline $50-64$ & $\begin{array}{c}0.11 \\
(0.17)\end{array}$ & $\begin{array}{c}-0.27 \\
(0.17)\end{array}$ & $\begin{array}{c}0.34 \\
(0.21)\end{array}$ \\
\hline $65+$ & $\begin{array}{l}0.45^{* *} \\
(0.14)\end{array}$ & $\begin{array}{c}-0.77^{* * *} \\
(0.16)\end{array}$ & $\begin{array}{l}0.66^{* *} \\
(0.21)\end{array}$ \\
\hline \multicolumn{4}{|l|}{ Health Status } \\
\hline Good/v. good health & $\begin{array}{c}0.13 \\
(0.11)\end{array}$ & $\begin{array}{r}-0.26^{*} \\
(0.11)\end{array}$ & $\begin{array}{l}0.49^{* * *} \\
(0.15)\end{array}$ \\
\hline Fair/bad/v.bad health & $\begin{array}{l}0.48^{* * *} \\
(0.12)\end{array}$ & $\begin{array}{c}-0.66^{* * * *} \\
(0.13)\end{array}$ & $\begin{array}{l}0.29+ \\
(0.16)\end{array}$ \\
\hline \multicolumn{4}{|l|}{ Health Limitations } \\
\hline Limitations & $\begin{array}{l}0.29^{* * *} \\
(0.09)\end{array}$ & $\begin{array}{c}-0.45^{* * *} \\
(0.09)\end{array}$ & $\begin{array}{l}0.45^{* * * *} \\
(0.12)\end{array}$ \\
\hline No limitations & $\begin{array}{c}0.23 \\
(0.20)\end{array}$ & $\begin{array}{c}-0.33 \\
(0.20)\end{array}$ & $\begin{array}{c}0.00 \\
(0.25)\end{array}$ \\
\hline \multicolumn{4}{|l|}{ Employment Status } \\
\hline In paid work & $\begin{array}{c}0.24^{*} \\
(0.12)\end{array}$ & $\begin{array}{c}-0.14 \\
(0.13)\end{array}$ & $\begin{array}{c}0.05 \\
(0.16)\end{array}$ \\
\hline In education & $\begin{array}{c}0.35 \\
(0.24)\end{array}$ & $\begin{array}{c}-0.45 \\
(0.29)\end{array}$ & $\begin{array}{c}0.22 \\
(0.35)\end{array}$ \\
\hline Unemployed & $\begin{array}{c}0.15 \\
(0.29)\end{array}$ & $\begin{array}{c}-0.46+ \\
(0.27)\end{array}$ & $\begin{array}{l}0.53+ \\
(0.30)\end{array}$ \\
\hline Retired & $\begin{array}{l}0.40^{* *} \\
(0.14)\end{array}$ & $\begin{array}{c}-0.79^{\text {**** }} \\
(0.15)\end{array}$ & $\begin{array}{l}0.77^{\text {*** }} \\
(0.21)\end{array}$ \\
\hline Disabled/long-term sick & $\begin{array}{c}-0.50 \\
(0.83)\end{array}$ & $\begin{array}{c}0.26 \\
(1.08)\end{array}$ & $\begin{array}{c}-1.12 \\
(1.01)\end{array}$ \\
\hline Others & $\begin{array}{c}0.32 \\
(0.29)\end{array}$ & $\begin{array}{c}-0.82^{* *} \\
(0.29)\end{array}$ & $\begin{array}{l}1.28^{* * *} \\
(0.37)\end{array}$ \\
\hline \multicolumn{4}{|l|}{ Subj. HH Income } \\
\hline Living comfortably & $\begin{array}{l}0.52+ \\
(0.27)\end{array}$ & $\begin{array}{c}-0.41 \\
(0.37)\end{array}$ & $\begin{array}{c}0.25 \\
(0.42)\end{array}$ \\
\hline Coping & $\begin{array}{c}0.26^{*} \\
(0.11)\end{array}$ & $\begin{array}{r}-0.24^{*} \\
(0.12)\end{array}$ & $\begin{array}{c}0.17 \\
(0.15)\end{array}$ \\
\hline Difficult & $\begin{array}{l}0.27+ \\
(0.15)\end{array}$ & $\begin{array}{c}-0.58^{* * * *} \\
(0.15)\end{array}$ & $\begin{array}{l}0.54^{* *} \\
(0.20)\end{array}$ \\
\hline Very difficult & $\begin{array}{c}0.26 \\
(0.26)\end{array}$ & $\begin{array}{c}-0.73^{* *} \\
(0.28)\end{array}$ & $\begin{array}{c}0.76^{*} \\
(0.32)\end{array}$ \\
\hline
\end{tabular}


TABLE 3. Continued

$\begin{array}{ll}\text { (1) } \Delta \text { 2008-2010 } & \text { (2) } \Delta \text { 2010-2012 }\end{array}$

(3) $\Delta$ 2012-2015

\section{Education}

Low

$0.24^{*}$

(0.09)

$-0.54^{* * *}$

$0.53^{* * *}$

Medium

$0.34+$

(0.20)

High

$0.47^{*}$

(0.21)

$-0.30$

(o.21)

$-0.08$

(0.13)

0.21

(0.26)

(0.23)

$-0.14$

(o.26)

Note: ESS, Portuguese Sample, rounds 1-7, unstandardised coefficients of interaction effect between subgroup and year of survey, with varying reference years, standard errors in parentheses, standard weights applied. ${ }^{+} p<0.10,{ }^{*} p<0.05,{ }^{* *} p<0.01, * 0.001$.

groups (Table 3, model 2). More specifically, and in line with Hypothesis 2, compared to $2010 / 11$, healthcare evaluations dropped in $2012 / 13$ by 0.8 scale points for individuals age 65 and older $(\beta=-.77, \mathrm{SE}=.16)$ and for retirees $(\beta=-.79$, $\mathrm{SE}=.15)$. Those in fair, bad or very bad health rated healthcare services 0.7 scale points lower $(\beta=-.66, \mathrm{SE}=.13)$ in $2012 / 13$ than in $2010 / 11$, while those with good and very good health lowered their evaluations by only 0.3 scale points $(\beta=-.26, \mathrm{SE}=.11)$. Ratings of healthcare services dropped particularly strongly for those reporting difficulties living on their present income (difficult: $\beta=-.58, \mathrm{SE}=.15$; very difficult: $\beta=-.73, \mathrm{SE}=.28$ ), those with 'other employment status' (mostly house workers and respondents looking after children) $(\beta=-.82, \mathrm{SE}=.29)$, and the lower educated $(\beta=-.54, \mathrm{SE}=.10)$. In contrast, the evaluations of the more socially advantaged, e.g. individuals with higher education, income and those in paid employment, show only minor and insignificant changes between 2010/11 and 2012/13.

In line with the results reported for the general population, the healthcare evaluations of most subgroups 'recovered' in 2015 to the level of 2010/11 (Table 3, model 3). For example, those with 'other employment status' rated the healthcare system 1.3 scale points higher in 2015 than in $2012 / 13(\beta=1.28$, $\mathrm{SE}=.37)$. Further, significant increases in healthcare evaluations between 2012/ 13 and 2015 are observed for the retired $(\beta=.77, \mathrm{SE}=.21)$ and individuals of 65 years of age and older $(\beta=.66, \mathrm{SE}=.21)$, those with health conditions limiting their daily activities $(\beta=.45, \mathrm{SE}=.12)$, those with lower education $(\beta=.53, \mathrm{SE}=.13)$, and those facing difficulties on their present income (difficult on present income: $\beta=.54, \mathrm{SE}=.20$; very difficult on present income: $\beta=.76, \mathrm{SE}=.32$ ).

There are exceptions to this trend, however. For example, the healthcare ratings of individuals with (fairly) bad health did not recover fully, at least until 2015. Notably, those reporting to be long-term sick or disabled evaluated 
healthcare services very negatively in 2015, with ratings 1.4 scale points $(\beta=-1.36, \mathrm{SE}=.73)$ lower than in $2008 / 09$, the pre-crisis period.

\subsection{Trends in healthcare evaluations: differences between subgroups}

Differences in subgroups' opinions of healthcare changed over time (Table 2, models 2-4). In line with Hypothesis 3, we find differences in the healthcare evaluations of groups with different health status and income were more pronounced after the implementation of the MoU measures. Firstly, with the implementation of the MoU measures, differences between health groups increased strongly, showing a very steep and gradual relationship between health status and healthcare evaluations in the second period of the economic crisis, i.e. between 2012 and 2015 (Table 2, model 4). Secondly, differences in healthcare evaluations between income groups became slightly stronger during the crisis, with those reporting difficulties living on their present household income more critical of the healthcare sector (Table 2, models 3/4).

Interestingly, we find a convergence in healthcare evaluations for specific groups despite initial differences before the economic crisis. For example, individuals with secondary education were more critical of health services than the lower educated before the economic crisis $(\beta=-.26, \mathrm{SE}=.10)$ and during the first crisis period $(\beta=.24, \mathrm{SE}=.12)$. But no significant differences between education groups were observed for the second period of the economic crisis $(\beta=.11, \mathrm{SE}=.15)$. Further, we find the younger and older age groups were more positive about Portuguese health services than the middle age groups. Interestingly, age differences were particularly strong in the period before the crisis but there were no significant differences between younger and middleaged groups in the second period of the crisis.

\subsection{Sensitivity check: evaluation of education system}

To test whether our results are institution-specific and refer to actual changes in the healthcare sector, we repeated our analysis for evaluations of the education system (Table $\mathrm{A}_{3}$ in supplementary online material). Overall, the trends in perceptions of these two public institutions are different. We find that the evaluations of the education system increased gradually until 2010 and, unlike healthcare evaluations, remained rather stable thereafter. In contrast to healthcare evaluations, differences between age groups did not change during the crisis period. Contrary to our results for healthcare evaluations, both middle and higher educated groups were more negative about the education system than lower educated groups. At the same time, and similar to findings on healthcare evaluations, differences in evaluations of the education system were stronger between different income groups for the two crisis periods together (2008-2015) and between groups of different health status in the second crisis 
period (2012-2015). In sum, these results show that ratings for health and education services differ. They strengthen the argument that attitudes are distinct and institution-specific and provide additional support for our findings on opinions of healthcare, proving our measurement to be sufficiently sensitive.

\section{Summary and discussion}

Previous research has indicated that public opinion on healthcare depends on the institutional structure of healthcare systems and individual characteristics connected to the interests and needs of particular subpopulations. Our study adds to the discussion by exploring changes in healthcare evaluations over time, using Portugal as an interesting test case. More specifically, we explored the effect of the economic crisis and the extent of austerity-oriented measures introduced in the Portuguese health sector on the public opinion towards healthcare. We began by examining the changes in legislation, healthcare spending, and access during the economic crisis and then empirically investigated changes in public opinion of the general population and specific groups using Portuguese data from the seven rounds of the European Social Survey (2002-2015).

In support of Hypothesis 1, we found healthcare evaluations steadily improved between 2002 and 2010 but dropped significantly in 2012/13 after the MoU. While this finding might not seem particularly surprising and complements previous research on the impact of institutional factors on public opinion (Wendt et al., 2010; Jordan, 2010), it is significant. The crisis per se and the domestically crafted, relatively mild austerity measures introduced at the beginning of the crisis did not negatively affect the public opinion on healthcare. Instead, our findings suggest that external measures, conditioned by the Troika and marked by austerity, with more severe cuts in public healthcare spending, led to a more negative perception of the Portuguese health system.

Our findings also indicate that the policy changes introduced under the MoU affected social groups differently, and this is reflected in changes in the opinions of different groups over time. In support of Hypothesis 2, we found the decrease in healthcare evaluations in 2012 was more severe for more vulnerable groups, especially older groups, those with poor health, low income and education, the retired and non-employed. In contrast, only minor and insignificant changes were observable for groups with higher income and education, and those in paid work. Our findings support research showing that the austerity reforms introduced in the European healthcare sectors during the crisis, at least in the short term, had a stronger and more negative effect on the most vulnerable social groups (Stuckler et al., 2011, 2017). Our findings also complement existing research on Portugal, which shows that the austerity-oriented health policies were associated with deteriorated access to medical services for the general population but had a more dramatic impact on vulnerable social groups 
(Sakellarides et al., 2014; Thomson et al., 2014; Legido-Quigley et al., 2016; Costa et al., 2017). The findings suggest policy changes introduced under the MoU, such as cuts in total and public healthcare spending and an increase in out-of-pocket payments through increased user fees, despite exemptions, particularly affected the most vulnerable. The drop in the healthcare evaluations of these subgroups could be seen as a direct result of their healthcare experience (e.g. difficulties in accessing care) and/or reflect their disappointed expectation that the NHS would deliver care when it was most needed.

In addition, and in line with Hypothesis 3, differences in the healthcare evaluations of the more and the less vulnerable social groups increased in 2012/13. For example, we found differences between individuals of different health status were particularly strong after the implementation of the majority of the MoU measures. Similarly, we found more pronounced differences between income groups. This is relevant when we remember that the Portuguese healthcare system has a dual structure, privileging particular social groups, i.e. those with social and private health insurance who are usually betteroff and less dependent on public health services. Therefore, our findings suggest that the austerity under MoU, which mainly targeted the public NHS system, accentuated the dual structure of the Portuguese system and affected more the most vulnerable subpopulations.

Interestingly, our findings show that evaluations worsened in 2012/13 only and improved thereafter, at least until 2015. This improvement in healthcare evaluations can be observed not only for the general population but also for the vulnerable groups, particularly those most affected by the economic crisis and changes in health policy measures, such as the old and retired, those with limitations in their daily activities due to health issues, and those with low income and education. This suggests that the MoU's austerity measures only had a short-term effect on the evaluations of the overall population and of the vulnerable groups. This could be explained by the gradual recovery of some of the healthcare system's key institutional characteristics, e.g. total healthcare spending, after the drop in 2012.

The timing of the specific MoU measures is another possible explanation of the trend in the evaluations. Most of the austerity measures, and some of the harshest ones such as increases in user fees, were implemented relatively shortly before the fieldwork of round $6(2012 / 13)$ of the ESS. Between round $6(2012 / 13)$ and round 7 (2015) fieldwork, the implemented measures targeted more specifically privileged social groups, i.e. those with social health insurance. The more vulnerable could see that others who were better off also had to accept cutbacks in their benefits (see Blekesaune, 2013), which could explain the improvement in the healthcare evaluations of the more vulnerable after 2012.

Other contextual, as well as psychological, factors might have played a role. It could be that the political and public discourse surrounding the 
austerity reforms in Portugal, which often described these reforms as 'necessary' and 'without alternative' (see Moury and Standring, 2017), led the Portuguese to accept the inevitability of change. Despite their adverse experiences with the healthcare system, in the course of the crisis, they may have tried to adapt to the changes and reform processes. As expectations are inversely related to the evaluation of public services (Schneider and Popic, 2018), an adaptation of expectations towards the healthcare system may have led to the 'recovery' of healthcare evaluations in 2015. It seems equally reasonable that public opinion may have improved in 2015, when the MoU's measures were almost completed, as the country had concluded the bailout agreement with the Troika. This may have generated relief and optimism among the Portuguese population.

However, and before any conclusions can be drawn from our results, we need to exclude any possible methodological reasons for our findings. The low response rate (43 per cent) and low sample size of the last round of the ESS in Portugal may have produced biased results. We used standard weights recommended by the ESS to correct for any biases; but more research, possibly in other survey studies, is clearly warranted to explore the validity of our findings, especially with respect to the recovery in healthcare evaluations in 2015 .

\subsection{Limitations}

Admittedly, our results are not without limitations. Firstly, we were not able to observe utilisation patterns or barriers that may hinder access to health services. Therefore, our results do not allow us to make conclusions about the particular challenges respondents face when accessing health services and how they affect their general perception of health services. Secondly, we were only able to control for socio-economic characteristics that often serve as a rough proxy for the type of healthcare received by the respondent. No information on the respondents' actual insurance status was available that was likely to have important implications for the perception of health services. The dual structure of the Portuguese healthcare system creates differences in healthcare access for different insurance types, and this changed during the crisis, possibly influencing perceptions of health services differently. Thirdly, we were not able to explore the respondents' expectations of the healthcare system because we lacked appropriate data. Therefore, it remains speculative as to whether lower expectations of the government's role in providing healthcare resulted in the 'recovery' in healthcare evaluations in 2015, or whether other factors triggered it. Lastly, and most importantly, we used cross-sectional data. This means any assumptions of causality must remain speculative; testing for intra-individual changes in evaluations across time would require the inclusion of relevant indicators in longitudinal survey studies. 


\section{Conclusion}

The findings of our study suggest that the austerity measures introduced under the Troika's bailout agreement in Portugal during the recent economic crisis worsened public views towards healthcare, including those of the most vulnerable social groups. This has important implications for policymakers. Austerity may threaten the welfare state by preventing social policy programmes from performing one of their key functions - providing healthcare to the most vulnerable when it is most needed. The worsening of the views of the most vulnerable towards healthcare as one of the largest welfare sectors could suggest a more general worsening of the welfare state image in the eyes of its most likely beneficiaries, and this could have detrimental consequences for the legitimacy of the welfare state as a whole. Even though these measures did not have a prolonged negative effect, it is noteworthy that the Portuguese system belongs to the most critically perceived healthcare systems in Western Europe (Schneider and Devitt, 2018a). The fact that public opinion had 'recovered' by the time most of the MoU measures were implemented should not conceal the fact that the public's opinion towards healthcare is still comparatively low, indicating a general dissatisfaction among the Portuguese with their healthcare services before and after the economic crisis.

However, these implications are provisional. More research is needed to analyze the different effects of the economic crisis on the public opinion towards welfare in a comparative perspective, taking changes in the public's normative expectations towards the welfare system, especially healthcare, into account. Even though, in the recent crisis-triggered welfare state restructuring, other countries followed similar paths that seemed independent of their previous policy choices (see Shahidi, 2015), our research suggests that public views of the policy responses may depend on the country-specific structure of the welfare provision. This implies that similar government responses may affect public opinion very differently across countries. Further comparative analyses of the particular policy interventions, and their effects on the welfare views of both the general population and specific social groups, will provide a more refined picture of public perception of crisis management, leading to more specific policy advice.

\section{Acknowledgements}

The authors would like to thank the editors of the Journal of Social Policy and the anonymous reviewers for their valuable comments on earlier drafts of this manuscript. For all statements of fact, data analyses and interpretation of results, the authors alone bear responsibility.

This research is part of the NORFACE Welfare State Futures funded research project 'The Paradox of Health State Futures' (HEALTHDOX) (EC ERA-Net Plus funding, grant agreement number 618106, file number 462-14-070). 


\section{Notes}

1 The two main 'subsystems' (since 2005) are ADSE (Assistência na Doença aos Servidores Civis do Estado), providing health insurance for civil servants and other public sector workers, and ADM (Assistência na Doença aos Militares), an insurance scheme for military personnel. The subsystems are financed by employee contributions and general taxation.

2 In the early 2000s, around 25 per cent of the Portuguese population was covered by the subsystems (Bentes et al., 2004), with about 15 per cent insured through private schemes (Guillén, 2002).

3 Wave-specific field work periods (FW), response rates (RR), and sample sizes (N) are as follows; wave 1: $\mathrm{FW}=26.09 .02-20.01 .03, \mathrm{RR}=68.8 \%, \mathrm{~N}=1,458$; wave 2: $\mathrm{FW}=15.10 .04-17.03 .05$, $\mathrm{RR}=71.2 \%, \mathrm{~N}=1,972$; wave $3: \mathrm{FW}=12.10 .06-28.02 .07, \mathrm{RR}=72.8 \% ; \mathrm{N}=2,095$; wave 4 : $\mathrm{FW}=09.10 .08-08.03 .09, \quad \mathrm{RR}=75.7 \%, \mathrm{~N}=2,295 ;$ wave $5: \mathrm{FW}=11.10 .10-23.03 .11$, $\mathrm{RR}=67.1 \%, \mathrm{~N}=2,100$; wave $6: \mathrm{FW}=24.10 .12-20.03 .13, \mathrm{RR}=77.1 \%, \mathrm{~N}=2,113$; wave 7 : $\mathrm{FW}=02.02 .15-30.11 .15, \mathrm{RR}=43 \%, \mathrm{~N}=1,238$.

4 Results of the multivariate regression analysis for each year are reported in the online supplementary material, Table A2.

\section{Supplementary material}

To view supplementary material for this article, please visit https://doi.org/10. $1017 /$ So047279418000818.

\section{References}

Afonso, A., Zartaloudis, S. and Papadopoulos, Y. (2015), 'How party linkages shape austerity politics: clientelism and fiscal adjustment in Greece and Portugal during the Eurozone crisis', Journal of European Public Policy, 22, 3, 315-334

Barr, N.A. (2001), The Welfare State as Piggy Bank: Information, Risk, Uncertainty, and the Role of the State, Oxford: Oxford University Press.

Barros, P.P. (2012a), 'Healthcare policy in tough times: the case of Portugal', Health Policy, $106,1,17-22$.

Barros, P.P. (2012b), 'Portugal's health policy under a financial rescue plan', Eurohealth, 18, 3, 10.

Barros, P.P. (2012c), 'Pharmaceutical market reforms in Portugal under the Memorandum of Understanding', Eurohealth, 18, 1, 33-36.

Bentes, M., Dias, C.M., Sakellarides, C. and Bankauskaite, V. (2004), Portugal: Health Care Systems in Transition, Brussels: European Observatory on Healthcare Systems and Policies.

Blekesaune, M. (2007), 'Economic conditions and public attitudes to welfare policies', European Sociological Review, 23, 3, 393-403.

Blekesaune, M. (2013), 'Economic strain and public support for redistribution: a comparative analysis of 28 European Countries', Journal of Social Policy, 42, 1, 57-72.

Borisova, L.V., Martinussen, P.E., Rydland, H.T., Stornes, P. and Eikemo, T.A. (2017), 'Public evaluation of health services across 21 European countries: the role of culture', Scandinavian Journal of Public Health, 45, 2, 132-139.

Costa, F.A., Teixeira, I., Duarte-Ramos, F., Proença, L., Pedro, A.R., Furtado, C., da Silva, J.A. and Cabrita, J. (2017), 'Effects of economic recession on elderly patients' perceptions of access to health care and medicines in Portugal', International Journal of Clinical Pharmacy, 39, 1, 104-112.

Doetsch, J., Pilot, E., Santana, P. and Krafft, T. (2017), 'Potential barriers in healthcare access of the elderly population influenced by the economic crisis and the troika agreement: a qualitative case study in Lisbon, Portugal', International Journal for Equity in Health, $16,1,184$. 
Eurofund (2014), Access to Healthcare in Times of Crisis, Luxembourg: Publications Office of the European Union.

European Commission (2011), 'Portugal: Memorandum of Understanding on Specific Economic and Policy Conditionality', http://ec.europa.eu/economy_finance/publications/ occasional_paper/2014/pdf/ocp202_en.pdf

Eurostat (2017), 'Eurostat Database', http://ec.europa.eu/eurostat/data/database.

Farnsworth, K. and Irving, Z. (2011), Social policy in challenging times: economic crisis and welfare systems. Bristol: Policy Press.

Footman, K., Roberts, B., Mills, A., Richardson, E. and McKee, M. (2013), 'Public satisfaction as a measure of health system performance: a study of nine countries in the former Soviet Union', Health Policy, 112, 1-2, 62-69.

Greve, B. (2014), 'Introduction: small European welfare states- impact of the fiscal crisis', Social Policy and Administration, 48, 4, 391-393.

Guillén, A.M., (2002), 'The politics of universalisation: establishing national health services in Southern Europe', West European Politics, 25, 4, 49-68.

Jordan, J. (2010), 'Institutional feedback and support for the welfare state: the case of national health care', Comparative Political Studies, 43, 7, 862-885.

Karanikolos, M., Mladovsky, P., Cylus, J., Thomson, S., Basu, S., Stuckler, D., Mackenbach, J.P. and McKee, M. (2013), 'Financial crisis, austerity, and health in Europe', The Lancet, 381, 9874, 1323-1331.

Kentikelenis, A., Karanikolos, M., Papanicolas, I., Basu, S., McKee, M. and Stuckler, D. (2011), 'Health effects of financial crisis: omens of a Greek tragedy', The Lancet, 378, 9801, 1457-1458.

Kohl, J. and Wendt, C. (2004), 'Satisfaction with health care systems. A comparison of EU countries', In Challenges for Quality of Life in the Contemporary World, Dordrecht: Kluwer Academic, 311-331.

Legido-Quigley, H., Karanikolos, M., Hernandez-Plaza, S., de Freitas, C., Bernardo, L., Padilla, B., Machado, R.S., Diaz-Ordaz, K., Stuckler, D. and McKee, M. (2016), 'Effects of the financial crisis and Troika austerity measures on health and health care access in Portugal', Health Policy, 120, 7, 833-839.

Margalit, Y. (2013), 'Explaining social policy preferences: evidence from the Great Recession', American Political Science Review, 107, 1, 80-103.

Missinne, S., Meuleman, B. and Bracke, P. (2013), 'The popular legitimacy of European healthcare systems: a multilevel analysis of 24 countries', Journal of European Social Policy, 23, 3, 231-247.

Mladovsky, P., Srivastava, D., Cylus, J., Karanikolos, M., Evetovits, T., Thomson, S. and McKee, M. (2012), Health Policy Responses to the Financial Crisis in Europe, Geneva: World Health Organization.

Mossialos, E. (1997), 'Citizens' views on health care systems in the 15 member states of the European Union', Health Economics, 6, 2, 109-116.

Moury, C. and Standring, A. (2017), 'Going beyond the Troika': power and discourse in Portuguese austerity politics', European Journal of Political Research, 56, 3, 660-679.

OECD (2017), 'OECD Health Statistics', http://www.oecd.org/els/health-systems/healthdata.htm

Pavolini, E. and Guillén, A. (2013), Health Care Systems in Europe Under Austerity: Institutional Reforms and Performance, Basingstoke: Palgrave Macmillan.

Pereirinha, J. (1995), 'Poverty and social exclusion in Portugal: a general overview of situations, processes and policies', Družboslovne razprave, 11, 19-20, 169-182.

Popic, T. and Schneider, S. (2018), 'An East-West comparison of healthcare evaluations in Europe: do institutions matter?', Journal of European Social Policy, 28, 5, 517-534.

Ronchi, S. (2018), 'Which roads (if any) to social investment? The recalibration of EU welfare states at the crisis crossroads (2000-2014)', Journal of Social Policy, 47, 3, 459-478. 
Roosma, F., Gelissen, J. and van Oorschot, W. (2013), 'The multidimensionality of welfare state attitudes: a European cross-national study', Social Indicators Research, 113, 1, 235-255.

Sakellarides, C., Castelo-Branco, L., Barbosa, P. and Azavedo, H. (2014), The Impact of the Crisis on the Healthcare System and Health in Portugal, Brussels: European Observatory on Healthcare Systems and Policies.

Schneider, S. and Devitt, C. (2018a), 'Accessing healthcare in times of economic growth and economic downturn: evidence from Ireland', Journal of European Social Policy, 28, 4, 357-369.

Schneider, S. and Devitt, C. (2018b), 'How do the Foreign-born rate host country health systems? evidence from Ireland', The Economic and Social Review, 49, 1, 45-71.

Schneider, S. and Popic, T. (2018), 'Cognitive determinants of healthcare system evaluationsA comparison of Eastern and Western European countries', Health Policy, 122, 3, 269-278.

Schrecker, T. and Bambra, C. (2015), How Politics Makes Us Sick: Neoliberal Epidemics, Basingstoke: Palgrave Macmillan.

Shahidi, F.V. (2015), 'Welfare capitalism in crisis: a qualitative comparative analysis of labour market policy responses to the Great Recession, Journal of Social Policy, 44, 4, 659-686.

Stuckler, D., Basu, S., Suhrcke, M., Coutts, A. and McKee, M. (2011), 'Effects of the 2008 recession on health: a first look at European data', The Lancet, 378, 9786, 124-125.

Stuckler, D., Reeves, A., Loopstra, R., Karanikolos, M. and McKee, M. (2017), 'Austerity and health: the impact in the UK and Europe', European Journal of Public Health, 27, 4, $18-21$.

Tavares, L.P. and Zantomio, F. (2017), 'Inequity in healthcare use among older people after 2008: the case of Southern European Countries', Health Policy, 121, 10, 1063-1071.

Thomson, S., Figueras, J., Evetovits, T., Jowett, M., Mladovsky, P., Maresso, A., Cylus, J., Karanikolos, M. and Kluge, H. (2014), Economic Crisis, Health Systems and Health in Europe: Impact and Implications for Policy, Copenhagen, Denmark: WHO Regional Office for Europe.

Thomson, S. and Mossialos, E. (2007), 'Regulating private health insurance in the European Union: the implications of single market legislation and competition policy', Journal of European Integration, 29, 1, 89-107.

Vis, B., Van Kersbergen, K. and Hylands, T. (2011), 'To what extent did the financial crisis intensify the pressure to reform the welfare state?', Social Policy and Administration, $45,4,338-353$.

Wendt, C., Kohl, J., Mischke, M. and Pfeifer, M. (2010), 'How do Europeans perceive their healthcare system? Patterns of satisfaction and preference for state involvement in the field of healthcare', European Sociological Review, 26, 2, 177-192. 